\title{
Mudanças climáticas e seus efeitos no rendimento de arroz irrigado no Rio Grande do Sul
}

\author{
Lidiane Cristine Walter ${ }^{(1)}$, Nereu Augusto Streck(2), Hamilton Telles Rosa(1), \\ Simone Erotildes Teleginski Ferraz ${ }^{(2)}$ e Jossana Ceolin Cera(2)
}

\begin{abstract}
(1)Instituto Federal Farroupilha, Campus Santo Augusto, Rua Fábio João Andolhe, no 1.100, Bairro Floresta, Caixa Postal 33, CEP $98590-000$ Santo Augusto, RS, Brasil. E-mail: lidiane.walter@iffarroupilha.edu.br, hamilton.rosa@iffarroupilha.edu.br (2)Universidade Federal de Santa Maria, Avenida Roraima, no 1.000, Campus Universitário, CEP 97105-900 Santa Maria, RS, Brasil. E-mail: nstreck2@yahoo.com.br, simonetfe@gmail.com, jossana.cera@gmail.com
\end{abstract}

Resumo - O objetivo deste trabalho foi estimar o rendimento de grãos de arroz irrigado nas regiões orizícolas do Estado do Rio Grande do Sul, em diferentes datas de semeadura, em cenário climático futuro - cenário A1B do Painel Intergovernamental sobre Mudanças Climáticas (IPCC) - e determinar as possíveis alterações no atual calendário de semeadura do arroz irrigado nesse cenário. O modelo SimulArroz foi usado, tendo-se considerado três grupos de maturação (precoce, médio e tardio) e sete datas de semeadura $(1 / 8,1 / 9,1 / 10,1 / 11$, $1 / 12,1 / 1$ e 1/2) para cada ano do cenário climático, nas seis regiões orizícolas do estado. Entre as regiões orizícolas, há variação do efeito da mudança no clima sobre o rendimento, em que a região da Fronteira Oeste é a menos favorecida e a Zona Sul, a mais favorecida no cenário futuro. As mudanças climáticas projetadas têm efeito positivo no rendimento de grãos de arroz irrigado no Estado do Rio Grande do Sul, principalmente no final do século 21, quando o período de semeadura poderá ser antecipado.

Termos para indexação: Oryza sativa, aquecimento global, época de semeadura, modelagem, modelo agrícola.

\section{Climate change and its effects on irrigated rice yield in the state of Rio Grande do Sul, Brazil}

\begin{abstract}
The objective of this work was to estimate the irrigated rice grain yield in the rice production regions of the state of Rio Grande do Sul, Brazil, in different sowing dates, in a future climatic scenario - the A1B scenario from the Intergovernmental Panel on Climate Change (IPCC) - and to determine possible changes in the current sowing calendar for irrigated rice in this scenario. The SimulArroz model was used, considering three maturity groups (early, middle, and late) and seven sowing dates $(8 / 1,9 / 1,10 / 1,11 / 1,12 / 1,1 / 1$, and 1/2) for each year of the climatic scenario, in the six rice production regions of the state. Among the rice production regions, there is a variation in the effect of climate change on yield, in which the Fronteira Oeste region is less favored and the Zona Sul region more favored in the future scenario. The projected climate change has a positive effect on rice grain yield in the state of Rio Grande do Sul, Brazil, mainly at the end of the $21^{\text {st }}$ century, when the sowing period may be anticipated.
\end{abstract}

Index terms: Oryza sativa, global warming, sowing time, modeling, crop model.

\section{Introdução}

As concentrações de gases de efeito estufa na atmosfera terrestre, como o dióxido de carbono $\left(\mathrm{CO}_{2}\right)$, o metano $\left(\mathrm{CH}_{4}\right)$ e o óxido nitroso $\left(\mathrm{N}_{2} \mathrm{O}\right)$, vêm aumentando continuamente, em grande parte, em razão das atividades antropogênicas, como uso de combustíveis fósseis e mudanças no uso da terra (Intergovernmental Panel on Climate Change, 2013). O incremento da concentração de $\mathrm{CO}_{2}$ tem efeito direto nas plantas, com possibilidade de aumento na taxa de crescimento e no rendimento das culturas no futuro, uma vez que o $\mathrm{CO}_{2}$ é o substrato primário para a fotossíntese (Streck, 2005). No entanto, o aumento da concentração de gases de efeito estufa pode elevar a temperatura do ar (Intergovernmental Panel on Climate Change, 2013), o que pode reduzir ou anular os efeitos benéficos do $\mathrm{CO}_{2}$ sobre as plantas, em decorrência do aumento da respiração e do encurtamento do ciclo de desenvolvimento das culturas (Streck, 2005), além de causar possíveis danos nos órgãos reprodutivos (Bouman et al., 2004).

O Rio Grande do Sul é o maior produtor nacional de arroz (Oryza sativa L.) e representa 69\% do arroz colhido no Brasil (Instituto Rio Grandense do 
Arroz, 2014). No Estado, são cultivados anualmente em torno de 1,1 milhão de hectares de arroz no sistema irrigado por inundação, em seis regiões orizícolas: Fronteira Oeste, Campanha, Depressão Central, Zona Sul, Planície Costeira Interna à Lagoa dos Patos e Planície Costeira Externa à Lagoa dos Patos (Instituto Rio Grandense do Arroz, 2014). Atualmente, a média do rendimento de grãos de arroz no Rio Grande do Sul é de, aproximadamente, $7,25 \mathrm{Mg} \mathrm{ha}^{-1}$ (Instituto Rio Grandense do Arroz, 2014), acima das médias brasileira, de 5,01 $\mathrm{Mg} \mathrm{ha}^{-1}$, e mundial, de 4,40 $\mathrm{Mg} \mathrm{ha}^{-1}$ (United States Department of Agriculture, 2014).

Estudos sobre o impacto das possíveis mudanças climáticas na agricultura brasileira têm aumentado nos últimos anos, e estimativas de rendimento, por meio de modelos matemáticos, têm sido obtidas em diversas regiões e para diferentes culturas (Siqueira et al., 2000; Assad et al., 2004; Streck \& Alberto, 2006a, 2006b; Streck et al., 2008, 2013a, 2013b; Walter et al., 2010). Para a cultura do arroz irrigado, Lago et al. (2008) simularam o desenvolvimento vegetativo no Município de Santa Maria, Rio Grande do Sul, e observaram que a duração do período vegetativo, em geral, diminui com o aumento da temperatura em cenários de mudanças climáticas. Walter et al. (2010) demonstraram que o rendimento potencial de grãos de arroz irrigado aumenta em cenários sintéticos de mudança climática em Santa Maria, na região central do Rio Grande do Sul. Contudo, é necessário que o rendimento de grãos seja avaliado em todas as regiões orizícolas do Estado.

Recentemente, o modelo SimulArroz (Streck et al., 2013a) foi desenvolvido e testado para simular o crescimento, o desenvolvimento e o rendimento da cultura do arroz em vários locais do Rio Grande do Sul, com uso de dados experimentais e de lavouras (Rosa, 2013). Esse modelo tem apresentado precisão satisfatória na simulação e na adequação para simulações em concentrações elevadas de $\mathrm{CO}_{2}$.

$\mathrm{O}$ objetivo deste trabalho foi estimar o rendimento de grãos de arroz irrigado nas regiões orizícolas do Estado do Rio Grande do Sul, em diferentes datas de semeadura, em cenário climático futuro - cenário A1B do Painel Intergovernamental sobre Mudanças Climáticas (IPCC) - e determinar as possíveis alterações no atual calendário de semeadura do arroz irrigado nesse cenário.

\section{Material e Métodos}

O estudo numérico foi realizado na área orizícola do Rio Grande do Sul. O Estado foi dividido em seis regiões produtoras de arroz, definidas pelo Instituto Rio Grandense do Arroz (Instituto Rio Grandense do Arroz, 2014): Fronteira Oeste, Campanha, Depressão Central, Planície Costeira Interna à Lagoa dos Patos, Planície Costeira Externa à Lagoa dos Patos e Zona Sul (Figura 1 A).

Os dados meteorológicos do cenário de mudança climática utilizados no presente trabalho foram gerados no Max Planck Institute for Meteorology, com uso do modelo acoplado Oceano-Atmosfera ECHAM5/ MPI-OM (Marsland et al., 2003). Os dados estão disponíveis para "download" no centro de distribuição de dados do IPCC. O cenário utilizado foi o A1B do quarto relatório do IPCC (Solomon et al., 2007). $\mathrm{O}$ cenário $\mathrm{A} 1 \mathrm{~B}$ foi selecionado por ser intermediário entre os mais pessimistas (cenários da família A) e os mais otimistas (cenários da família B), e descreve um mundo futuro de crescimento econômico muito rápido, com uso equilibrado de combustíveis de todas as fontes energéticas, fósseis e não fósseis (Solomon et al., 2007).

A conversão dos dados climáticos para o formato de entrada no modelo agrícola foi realizada e disponibilizada pelo Grupo de Pesquisas Climáticas (GPC) da Universidade Federal de Santa Maria. Dados globais climáticos são disponibilizados em formato de grade, com um valor para cada $2,5 \times 2,5^{\circ}$ de latitude/ longitude (aproximadamente $250 \mathrm{~km}$ ). Portanto, para sua utilização em estudos regionais, aplicou-se a técnica de "downscaling". Esta técnica consiste em utilizar os dados globais como condição de contorno em um modelo regional e em executar o modelo regional em uma grade espacial menor. Para gerar os novos dados, regionalizados para as regiões orizícolas do Rio Grande do Sul, foi utilizado o modelo climático regional RegCM3 do International Centre for Theoretical Physics (ICTP) - com grade $45 \times 45 \mathrm{~km}$ de latitude/longitude, o que faz uma regionalização ("downscaling" dinâmico).

Os dados do cenário climático futuro utilizados foram: temperatura mínima e máxima diária do ar, radiação solar diária e concentração anual de $\mathrm{CO}_{2}$, no período de 1960 a 2099 (140 anos). Essa série de dados foi agrupada em quatro intervalos temporais equidistantes, cada um com 35 anos, o que representa 
o clima passado (de 1960 a 1994, ano médio: 1977), o clima atual (de 1995 a 2029, ano médio: 2012) e dois períodos do clima futuro: em meados do século 21 (2030 a 2064, ano médio: 2047) e ao final do século (2065 a 2099, ano médio: 2082). Os dados meteorológicos cobrem toda a região orizícola do Estado, por meio
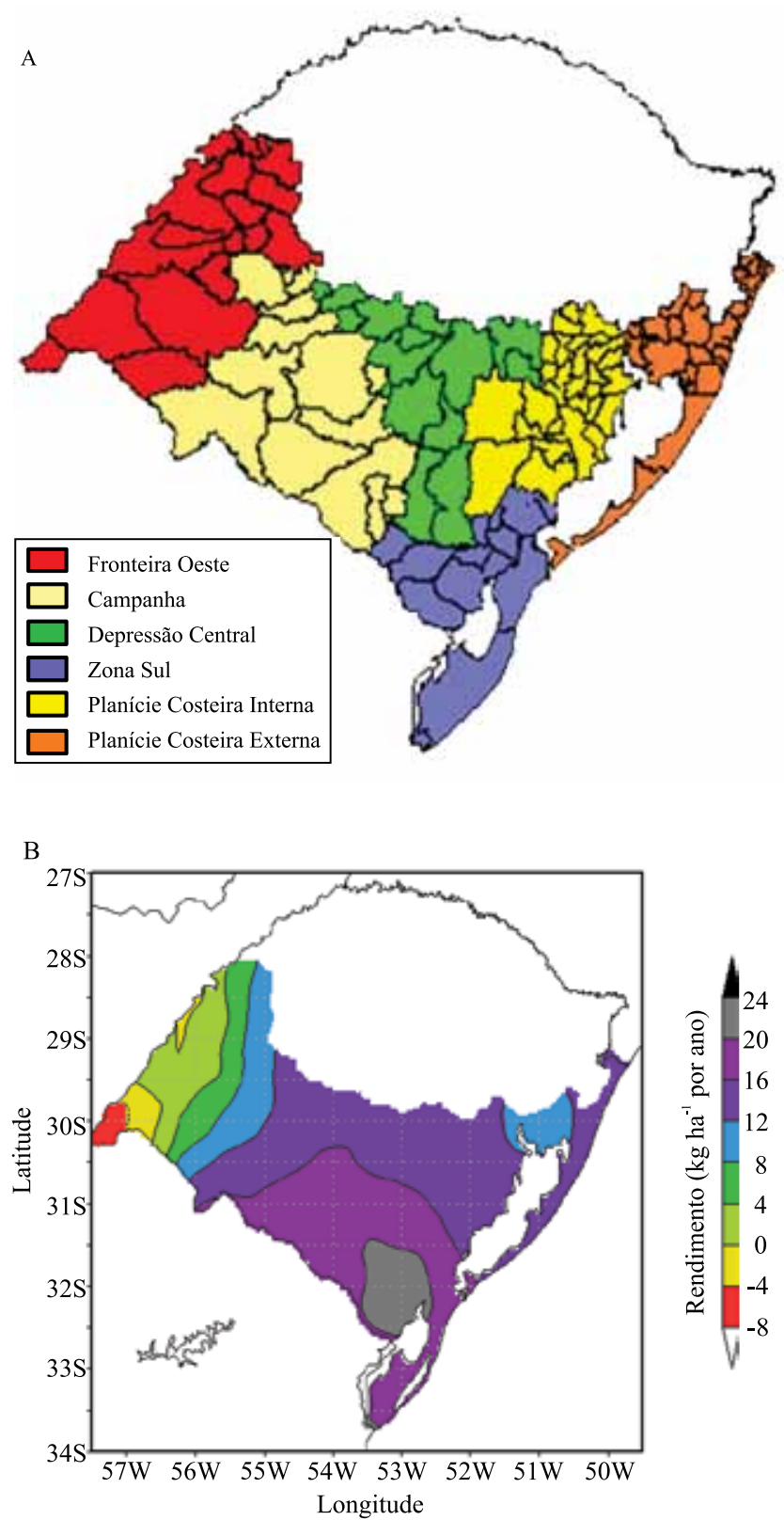

Figura 1. Representação das regiões orizícolas do Estado do Rio Grande do Sul (A) (Fonte: IRGA) e tendência anual do rendimento de grãos de arroz (Oryza sativa) irrigado (B) no período de 1960-2099, na simulação com o modelo SimulArroz, no cenário climático A1B (Solomon, 2007). de pontos de coordenadas geográficas, num total de 18 pontos.

O modelo agrícola usado foi o SimulArroz (Streck et al., 2013a). Para rodar o SimulArroz, foi necessário informar o conjunto de dados meteorológicos do cenário climático e os dados referentes à cultura do arroz: cultivar ou grupo de maturação, nível tecnológico da lavoura, data de semeadura, número de safras a serem simuladas, concentração de $\mathrm{CO}_{2}$ atmosférico e densidade de plantas. Após cada simulação, os resultados de rendimento de grãos, biomassa de cada compartimento da planta e esterilidade de espiguetas, podem ser armazenados na forma gráfica ou numérica. O modelo foi rodado para três grupos de maturação de arroz: precoce, médio e tardio, que correspondem aos grupos II, III e IV do zoneamento agrícola de risco climático para a cultura no Rio Grande do Sul (Brasil, 2013). As simulações foram feitas em sete datas de semeadura, de agosto a fevereiro, com intervalo de um mês entre as datas $(1 / 8,1 / 9,1 / 10,1 / 11,1 / 12,1 / 1$ e $1 / 2)$, no nível tecnológico potencial. As variáveis analisadas foram rendimento de grãos de arroz, esterilidade de espiguetas por frio e por calor, e danos causados por geada.

Para testar o desempenho do SimulArroz em prever o rendimento de grãos de arroz nas regiões orizícolas, foram comparados os dados de rendimento de grãos simulado pelo SimulArroz entre as safras de 1984/1985 e 2013/2014 e os dados de rendimento de grãos observados pelo Instituto Rio Grandense do Arroz, no mesmo período. As estatísticas usadas no teste foram o bias e a raiz do quadrado médio do erro (RQME) (Streck \& Alberto, 2006a).

Em cada série histórica de dados de rendimento, gerada pelas rodadas do modelo ao longo dos anos do cenário climático, calculou-se a tendência para cada ponto de grade, por meio da análise do coeficiente angular da regressão linear entre rendimento x anos, tendo-se gerado um mapa das tendências. Foram calculados: médias de rendimento potencial de grãos a $13 \%$ de umidade do grão; número de espiguetas produzidas; e esterilidade por frio e por calor, para todo o Estado e para cada região orizícola (média dos grupos de maturação), em cada período. Para o cálculo da média da região, não foram considerados os pontos próximos do limite de transição entre as regiões. Para a representação cartográfica, foi criada uma máscara para o Estado do Rio Grande do Sul, com uso da ferramenta 
"The Grid Analysis and Display System" (GrADS), versão 2.0 (Brian Doty and the Institute of Global Environment and Society, Calverton, MD, EUA).

\section{Resultados e Discussão}

A concentração do $\mathrm{CO}_{2}$ atmosférico apresenta elevação constante no cenário A1B e chega a valores próximos de $700 \mathrm{ppm}$ até o final do século 21 . A temperatura mínima do ar teve aumento de 2,7 a $3,7^{\circ} \mathrm{C}$, nas regiões da Zona Sul e da Fronteira Oeste, respectivamente; já, para a temperatura máxima, o aumento foi de 2,4 a $2,9^{\circ} \mathrm{C}$, nas regiões da Zona Sul e da Fronteira Oeste, respectivamente. A temperatura mínima é menor nas regiões da Campanha e da Depressão Central, e os valores mais altos de temperatura mínima são observados nas regiões da Fronteira Oeste, da Zona Sul e da Planície Costeira Externa à Lagoa dos Patos. A temperatura máxima é mais elevada na Fronteira Oeste e mais baixa na Zona Sul. Para a radiação solar, os níveis são elevados na Fronteira Oeste e na Zona Sul, enquanto os menores valores ocorrem na região da Planície Costeira Interna à Lagoa dos Patos. A radiação solar incidente no cenário apresenta pequena tendência de redução ao longo dos anos, principalmente no primeiro semestre, com redução mais marcante no período de 2030 a 2064, em fevereiro, em todas as regiões.

A comparação dos dados de rendimento de grãos simulado pelo SimulArroz com os registrados pelo Instituto Rio Grandense do Arroz entre as safras de 1984/1985 e 2013/2014 indica desempenho satisfatório do modelo nas regiões orizícolas, com bias de 0,033 a -2,206 e RQME de 0,83 a 1,37 $\mathrm{Mg} \mathrm{ha}^{-1}$ na Fronteira Oeste e na Zona Sul, respectivamente. Entre as seis regiões orizícolas, o SimulArroz subestimou os dados observados na Planície Costeira Externa à Lagoa dos Patos e na Zona Sul, mas capturou a variabilidade interanual, sendo, portanto, apropriado para o presente trabalho.

Na maior parte da região orizícola do Rio Grande do Sul, o rendimento médio de grãos mostra tendência de aumento, com destaque para a região da Zona Sul, que apresenta maior incremento; a exceção é parte da Fronteira Oeste, onde há tendência de redução do rendimento (Figura $1 \mathrm{~B}$ ). $\mathrm{O}$ incremento anual no rendimento de grãos varia de $3,3 \mathrm{~kg} \mathrm{ha}^{-1}$, na média da região da Fronteira Oeste, a 20,5 $\mathrm{kg} \mathrm{ha}^{-1}$ na média da
Zona Sul, sendo que as demais regiões apresentam incrementos similares, com valores entre 13,9 e $15,4 \mathrm{~kg} \mathrm{ha}^{-1}$ por ano, ao longo do cenário climático. As tendências verificadas na região da Fronteira Oeste e da Zona Sul do Estado podem ser explicadas pelas variáveis meteorológicas de radiação solar e temperatura do ar. Ambas as regiões destacadas apresentam elevados e os maiores índices de radiação solar do Estado, com média climatológica de 23,5 a $25 \mathrm{MJ} \mathrm{m}^{-2}$ por dia em dezembro (Wrege et al., 2011), tendo, portanto, alto potencial produtivo (Bouman et al., 2004). Atualmente, na região da Fronteira Oeste, obtém-se elevados valores de rendimento de grãos de arroz irrigado, em torno de $8 \mathrm{Mg} \mathrm{ha}^{-1}$ nas últimas safras (Instituto Rio Grandense do Arroz, 2014), pelas condições favoráveis de radiação solar. Já na Zona Sul, apesar da elevada disponibilidade de radiação solar, observa-se alto risco de frio (Mota et al., 1999; Steinmetz et al., 2003), que causa esterilidade de espiguetas e provoca maior variabilidade interanual do rendimento de grãos. Com o incremento da temperatura do ar no cenário climático futuro, a Zona Sul do Estado passa a apresentar condição mais favorável ao cultivo do arroz irrigado, com menos danos causados pelas baixas temperaturas. Na região da Fronteira Oeste, o aumento da temperatura pode acarretar valores prejudiciais à cultura do arroz, pois aumenta a esterilidade de espiguetas causada pelo calor, que se intensifica com temperaturas entre 35 e $36,6^{\circ} \mathrm{C}$ (Bouman et al., 2004; Matsui et al., 1997).

De maneira geral, o rendimento de grãos de arroz irrigado é afetado positivamente com o passar dos anos do cenário climático, principalmente no último período, de 2065 a 2099 (Figura 2). A data de semeadura também apresentou grande influência no rendimento de grãos, sendo que semeaduras realizadas entre $1^{\circ} \stackrel{ }{ }$ de setembro e $1^{\circ}$ de novembro apresentam elevados rendimentos, acima de $8 \mathrm{Mg} \mathrm{ha}^{-1}$ em todos os períodos; para $1^{\circ}$ de agosto e $1^{\circ}$ de dezembro, os rendimentos são elevados somente a partir dos períodos de 2030-2064 e de 2065-2099, respectivamente. O aumento no rendimento de grãos decorre do aumento na concentração de $\mathrm{CO}_{2}$ ao longo dos anos, no cenário climático, uma vez que a maior taxa fotossintética em ambientes com elevada concentração de $\mathrm{CO}_{2}$ favorece a produção de biomassa vegetal e o rendimento de grãos (Krishnan et al., 2007).

O rendimento de grãos em arroz é afetado pela temperatura do ar, que causa a esterilidade das 

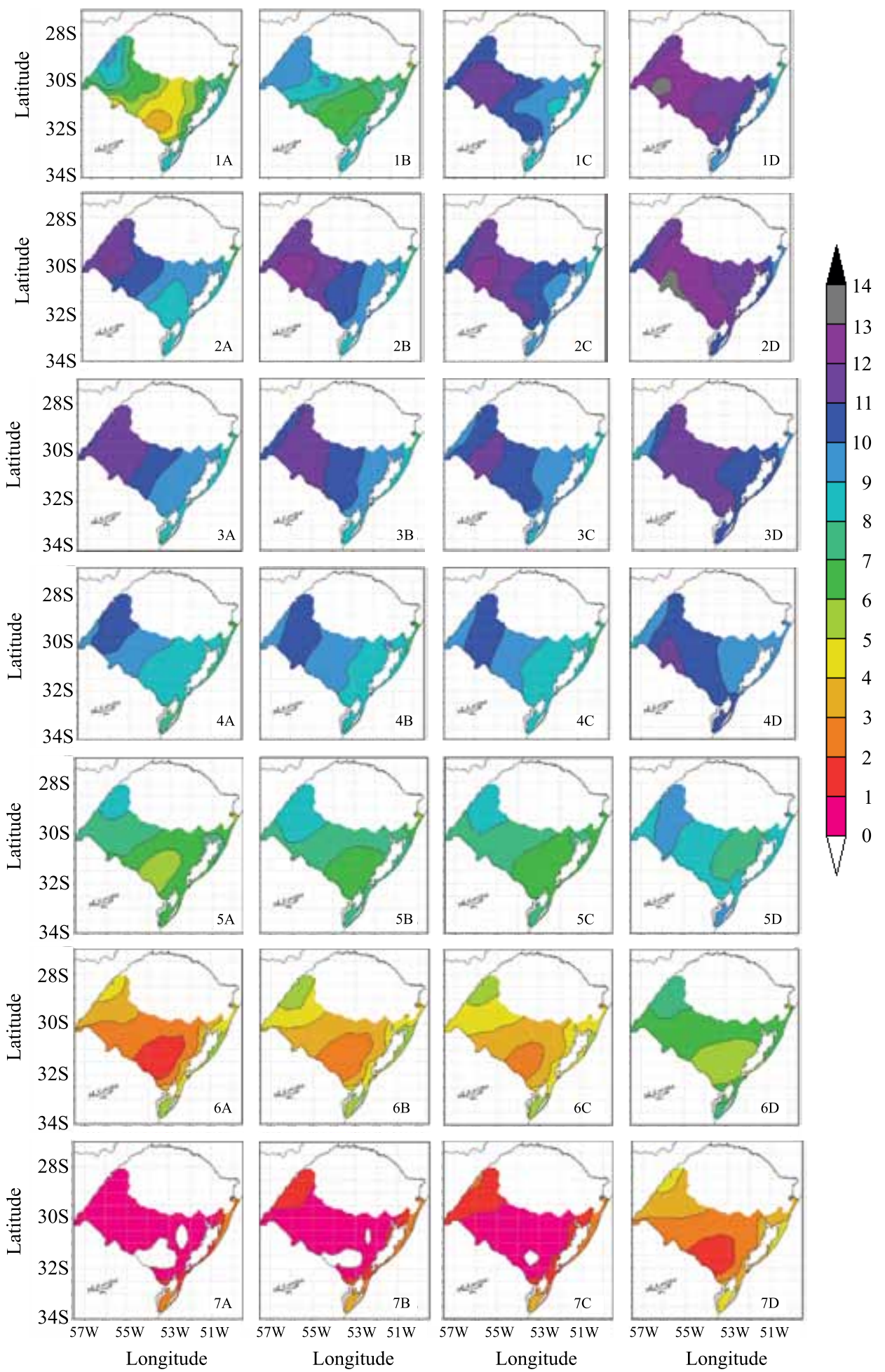

Figura 2. Rendimento de grãos de arroz (Oryza sativa) irrigado com semeadura no primeiro dia de agosto (1), setembro (2), outubro (3), novembro (4), dezembro (5), janeiro (6) e fevereiro (7), no Estado do Rio Grande do Sul, nos períodos de 1960-1994 (A), 1995-2029 (B), 2030-2064 (C) e 2065-2099 (D), simulado com o modelo SimulArroz, no cenário climático A1B (Solomon, 2007). 
espiguetas em condições de temperaturas muito baixas ou muito altas, bem como pelos danos causados por geadas (Matsui et al., 1997; Bouman et al., 2004). $\mathrm{O}$ incremento da temperatura do ar ao longo do cenário climático, apesar de aumentar a esterilidade de espiguetas ocasionada pelo calor, reduz os danos das baixas temperaturas nas lavouras de arroz (Figura 3). Nessas condições, o rendimento potencial de grãos é maior, pois os danos causados por baixas temperaturas no cenário atual são mais significativos do que os causados pelo calor no cenário futuro, o que faz com que as perdas sejam menores em temperaturas mais elevadas.

Outro fator importante para a definição do rendimento da lavoura de arroz irrigado é a influência de geadas sobre a cultura. Percebe-se que os eventos de geada reduzem a média do rendimento, principalmente nos primeiros períodos avaliados e nas semeaduras de agosto (quando o dano acontece nos estádios iniciais do desenvolvimento), e de janeiro e fevereiro (quando a geada prejudica a cultura em estádio de desenvolvimento mais avançado) (Figura 3). Quando o modelo identifica, durante o ciclo da cultura, uma condição de ocorrência de geada por um período de quatro dias consecutivos, é registrada a morte das plantas pelo dano causado, o que encerra o ciclo da cultura naquela safra. Essa condição no modelo faz com que o rendimento médio de grãos seja bastante reduzido nas datas de semeadura, em que a ocorrência de geada é mais provável (agosto, janeiro e fevereiro). O dano da geada diminui na medida em que a temperatura do ar se eleva, no cenário futuro.

No período de 1960-1994, para semeadura em agosto, observam-se rendimentos considerados baixos para o potencial produtivo da cultura, com pequenas áreas de rendimento mais elevado na Fronteira Oeste, na Zona Sul e na Planície Costeira Externa à Lagoa dos Patos (Figura 2). Ao se avançar nos períodos do cenário, verifica-se aumento gradual das áreas com rendimento de grãos muito elevado (acima de $8 \mathrm{Mg} \mathrm{ha}^{-1}$ ), com tendência de aumento em direção ao oeste do Estado. Esses resultados são indicativos de que as elevadas perdas de rendimento decorrentes de baixas temperaturas na semeadura de agosto (Figura 3 ), nos dois primeiros períodos do cenário, devem diminuir significativamente até o final do século, o que permite a antecipação do período recomendado para a semeadura do arroz irrigado.
A simulação do rendimento potencial de grãos com semeadura em setembro (Figura 2) sugere que semeaduras realizadas nesse mês resultam em elevados índices de rendimento de grãos (acima de $8 \mathrm{Mg} \mathrm{ha}^{-1}$ ) nos quatro períodos, em todas as regiões orizícolas do Estado, exceto numa pequena área do extremo leste, na região da Planície Costeira Externa à Lagoa dos Patos. Setembro representa o início do período atualmente recomendado para semeadura do arroz irrigado no Rio Grande do Sul (Brasil, 2013). No período de 1960-1994, a região da Fronteira Oeste se destaca com os mais elevados níveis de rendimento de grãos na semeadura de setembro, o que está de acordo com os dados históricos de safra registrados para o período equivalente (Instituto Rio Grandense do Arroz, 2014). Observa-se que a área com o maior rendimento de grãos se desloca da região da Fronteira Oeste em direção à Campanha e ao centro do Estado, e que ela abrange uma maior extensão, na medida em que o tempo passa, ao longo da série de anos do cenário climático avaliado. Esses resultados são indicativos de que as semeaduras em setembro continuarão sendo recomendadas nesse cenário, com altos rendimentos. No entanto, a região do extremo oeste do Rio Grande do Sul poderá apresentar pequena redução no rendimento de grãos, pois o aumento da temperatura do ar no final do século deverá aumentar a esterilidade de espiguetas ocasionada pelo calor, nessa região (Figura 3). Os valores de rendimento de grãos na semeadura de setembro variam entre $7,8 \mathrm{e}$ $12,6 \mathrm{Mg} \mathrm{ha}^{-1}$ no período atual (1995-2029) e entre 9,2 e 13,2 $\mathrm{Mg} \mathrm{ha}^{-1}$ ao final desse século (2065-2099).

$\mathrm{O}$ rendimento de grãos de arroz irrigado simulado para a semeadura em outubro (Figura 2) mantém-se elevado em todo o Estado durante o cenário avaliado, com valores entre 7,3 e $12 \mathrm{Mg} \mathrm{ha}^{-1}$. Em novembro, os valores de rendimento de grãos continuam elevados, entre 5,8 e 11,2 $\mathrm{Mg} \mathrm{ha}^{-1}$, porém abaixo do observado para setembro e outubro. Tanto para a semeadura de outubro quanto para a de novembro, a região da Fronteira Oeste se destaca com os maiores rendimentos nos períodos de 1969-1994 e 1995-2029, tendo sido superada a partir daí pelas demais regiões; ao final do século, os valores de rendimento de grãos dessa região são os menores, quando comparados aos das demais. No período de 2065 a 2099, a área com o mais alto rendimento se expande pelas regiões da Campanha, da Depressão Central e da Zona Sul. Constata-se a menor 

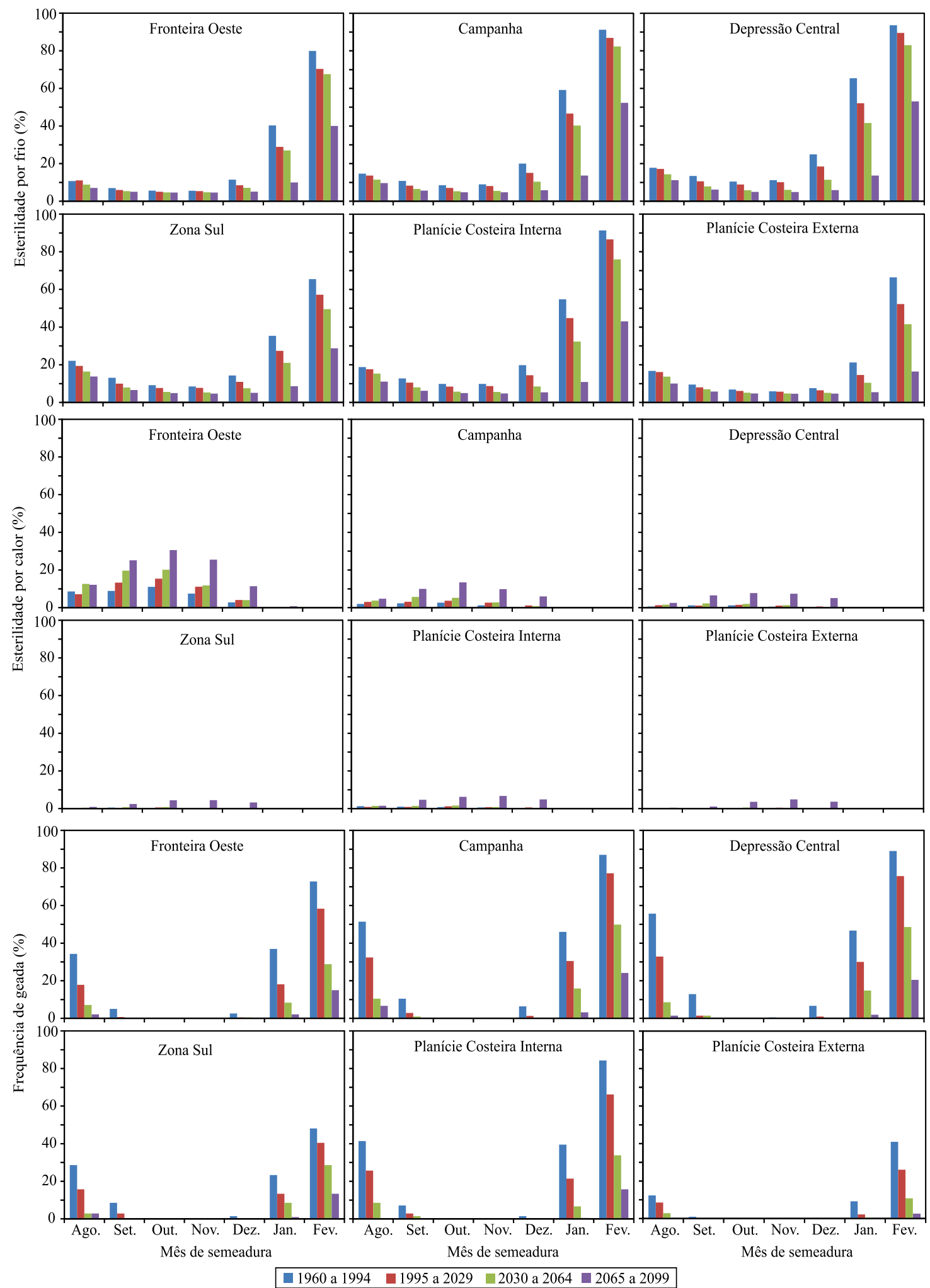

Figura 3. Esterilidade de espiguetas de arroz (Oryza sativa) causada por temperaturas baixas ou elevadas, e frequência de anos com ocorrência de danos causados por geada, em diferentes datas de semeadura, em quatro períodos do cenário A1B (Solomon, 2007), nas seis regiões orizícolas do Estado do Rio Grande do Sul. Semeaduras realizadas no primeiro dia de cada mês. 
tendência de crescimento do rendimento na Fronteira Oeste, em relação às demais regiões ao longo dos anos do cenário (Figura $1 \mathrm{~B}$ ).

A região da Fronteira Oeste, atualmente, já apresenta elevados rendimentos de arroz, tendo alcançado valores em torno de $8 \mathrm{Mg} \mathrm{ha}^{-1}$ (Instituto Rio Grandense do Arroz, 2014), e pode estar produzindo próximo ao seu potencial produtivo, uma vez que apresenta menor crescimento nos cenários futuros, mesmo com aumento da concentração de $\mathrm{CO}_{2}$. Além disso, o aumento da temperatura do ar previsto no cenário A1B teve efeito mais expressivo na região da Fronteira Oeste, onde os incrementos de temperatura do ar ocasionaram maior esterilidade de espiguetas por calor (Figura 3), o que compromete o rendimento de grãos. Segundo Matsui et al. (1997), temperaturas de $35^{\circ} \mathrm{C}$ durante a antese podem causar de 20 a $30 \%$ de esterilidade de espiguetas em arroz irrigado. Matthews et al. (1997), ao utilizar modelos de simulação de rendimento do arroz, também encontraram diferenças de rendimento em resposta a aumentos de temperatura. Os autores concluíram que a quantidade de dias com temperatura acima da ótima aumentou a esterilidade de espiguetas, o que confirma os resultados de menor incremento no rendimento de grãos na região da Fronteira Oeste, onde a esterilidade pelo calor é maior (Figura 3).

A partir de dezembro (Figura 2), o rendimento potencial de grãos diminui em todas as regiões orizícolas do Estado. Os valores situam-se entre 3,9 e 9,2 $\mathrm{Mg} \mathrm{ha}^{-1}$, com os maiores valores para a Fronteira Oeste e os menores rendimentos entre as Planícies Costeiras (Interna e Externa à Lagoa dos Patos) e a Depressão Central, de acordo com o período considerado.

As simulações com semeadura em janeiro e fevereiro resultaram nos menores valores de rendimento de grãos. Nessas datas de semeadura, muitos anos apresentam rendimento igual a zero, principalmente nos primeiros anos do cenário climático, quando a esterilidade de espiguetas por frio e a frequência de anos com morte das plantas por geada (Figura 3) causaram danos severos, com valores médios próximos a $100 \%$ de perda, o que contribuiu para diminuir a média de rendimento. As semeaduras em janeiro e fevereiro não são, atualmente, recomendadas para o arroz irrigado no Rio Grande do Sul (Brasil, 2013), pois os estádios de maior sensibilidade das plantas às baixas temperaturas (antese) ocorreriam em momentos com temperaturas prejudiciais. A partir de janeiro, a radiação solar disponível no Estado decresce, e, assim, a cultura terá um potencial produtivo mais baixo se for semeada tardiamente, já que a disponibilidade de radiação solar é que define o número total de espiguetas produzidas (Carmona et al., 2002; Bouman et al., 2004). Com a redução da radiação solar, por consequência, a temperatura do ar também diminui, e, mesmo no caso de cenários futuros, quando as temperaturas deverão ser mais elevadas, estima-se elevada esterilidade de espiguetas e danos por geada nas semeaduras de janeiro e fevereiro (Figura 3). Com o incremento de temperatura no último período do cenário climático (2065 a 2099), o rendimento de grãos estimado é mais elevado nas semeaduras de janeiro e fevereiro (Figura 2). Entretanto, os valores em torno de 5 a $6 \mathrm{Mg} \mathrm{ha}^{-1}$ para janeiro e um máximo de 4,2 $\mathrm{Mg} \mathrm{ha}^{-1}$ para fevereiro são baixos, em se tratando de rendimento potencial de grãos de arroz irrigado para o Rio Grande do Sul.

Para a Zona Sul, é estimado o maior incremento de rendimento, com tendência de aumento de, aproximadamente, $20 \mathrm{~kg} \mathrm{ha}^{-1}$ a cada ano do cenário climático (Figura 1 B). Essa região se caracteriza pelo elevado risco de frio, em razão das baixas temperaturas mínimas absolutas (Mota et al., 1999; Steinmetz et al., 2003), o que faz com que, atualmente, a Zona Sul apresente grande variabilidade interanual no rendimento de grãos (Instituto Rio Grandense do Arroz, 2014). Com a temperatura do ar mais elevada, no cenário de mudança climática utilizado no presente trabalho, o risco de frio diminui e as temperaturas tendem a ficar mais próximas da temperatura ótima para o crescimento e o desenvolvimento da cultura do arroz irrigado, que varia entre 23 e $30^{\circ} \mathrm{C}$ nas diferentes fases do ciclo (Lago et al., 2008). Esse fato, associado à elevada disponibilidade de radiação solar da Zona Sul do Estado (Mota, 1995; Wrege et al., 2011), faz com que essa região tenha potencial de aumento no rendimento de grãos de arroz irrigado no cenário A1B.

Estudos realizados em diferentes locais têm mostrado resultados similares. No Japão, Iizumi et al. (2011) relataram aumento de $26,9 \%$ no rendimento de grãos de arroz, em uma região do país, e redução de $0,8 \%$, em outra região, explicada pelo aumento dos dias com temperatura elevada, o que aumenta a esterilidade das espiguetas. Já na Índia, Kumar et al. (2014) verificaram tendência de redução no rendimento de 
aproximadamente $2 \%$, com apenas $1^{\circ} \mathrm{C}$ de elevação na temperatura média máxima, enquanto Krishnan et al. (2007) estimaram um incremento de mais de $56 \%$ em estudo de simulação com o modelo InfoCrop, no leste da país. Também foram relatados aumentos na China, com rendimento de arroz 16\% maior em cenário de mudança climática (Yang et al., 2006).

Deve-se levar em consideração o fato de que novas cultivares e técnicas poderão ser desenvolvidas no futuro, o que permite alterações no potencial produtivo da cultura do arroz irrigado, no Rio Grande do Sul. Os modelos agrícolas, inclusive o SimulArroz, tem uma limitação geral que é a dependência de parâmetros genéticos, os quais podem mudar à medida que novas cultivares são lançadas no mercado. Além disso, os modelos agrícolas têm dificuldade em capturar mudanças de manejo nas lavouras, que possam ocorrer no futuro. Mesmo com essas limitações, os modelos agrícolas são ferramentas que podem auxiliar no entendimento da dinâmica e da complexidade dos agroecossistemas frente a possíveis mudanças no clima regional.

\section{Conclusões}

1. As mudanças climáticas projetadas no cenário A1B do quarto relatório do Painel Intergovernamental sobre Mudanças Climáticas (IPCC) tem efeito positivo no rendimento de grãos de arroz irrigado no Estado do Rio Grande do Sul, pela simulação com o modelo SimulArroz.

2. Entre as regiões orizícolas do Rio Grande do Sul, há variação dos efeitos das mudanças no clima sobre o rendimento de arroz, em que a Fronteira Oeste é a menos favorecida e a Zona Sul, a mais favorecida no cenário futuro.

3. Com as mudanças climáticas projetadas no cenário A1B, principalmente no final do século 21, o período favorável para a semeadura do arroz no Rio Grande do Sul poderá ser antecipado, com início em agosto.

\section{Agradecimentos}

À Coordenação de Aperfeiçoamento de Pessoal de Nível Superior (Capes) e ao Conselho Nacional de Desenvolvimento Científico e Tecnológico (CNPq), pela concessão de bolsas.

\section{Referências}

ASSAD, E.D.; PINTO, H.S.; ZULLO JUNIOR, J.; ÁVILA, A.M.H. Impacto das mudanças climáticas no zoneamento agroclimático do café no Brasil. Pesquisa Agropecuária Brasileira, v.39, p.1057-1064, 2004. DOI: 10.1590/S0100-204X2004001100001.

BOUMAN, B.A.M.; KROPFF, M.J.; TUONG, T.P.; WOPEREIS, M.C.S.; BERGE, H.F.M. ten; LAAR, H.H. van. ORYZA 2000: modeling lowland rice. Version 2.12. Metro Manila: International Rice Research Institute, 2004. Available at: <http://www. knowledgebank.irri.org/oryza2000/default.htm>. Accessed on: 20 May 2010.

BRASIL. Ministério da Agricultura, Pecuária e Abastecimento. Secretaria de Política Agrícola. Portaria $n^{\circ} 267$ de 5 de dezembro de 2013. Aprova o zoneamento agrícola de risco climático para a cultura de arroz irrigado no Estado do Rio Grande do Sul, ano-safra 2013/2014. Diário Oficial [da] República Federativa do Brasil, 6 dez. 2013. Seção 1.

CARMONA, L. de C.; BERLATO, M.A.; BERGONCI, J.I. Relação entre elementos meteorológicos e rendimento do arroz irrigado no Estado do Rio Grande do Sul. Revista Brasileira de Agrometeorologia, v.10, p.289-294, 2002.

IIZUMI, T.; YOKOZAWA, M.; NISHIMORI, M. Probabilistic evaluation of climate change impacts on paddy rice productivity in Japan. Climatic Change, v.107, p.391-415, 2011. DOI: 10.1007/ s10584-010-9990-7.

INSTITUTO RIO GRANDENSE DO ARROZ. Safras. Porto Alegre: Irga, 2014. Disponível em: <http://www.irga.rs.gov.br/ conteudo/4215/safras $>$. Acesso em: 11 out. 2014.

INTERGOVERNMENTAL PANEL ON CLIMATE CHANGE. Summary for policymakers. In: STOCKER, T.F.; QIN, D.; PLATTNER, G.-K.; TIGNOR, M.; ALLEN, S.K.; BOSCHUNG, J.; NAUELS, A.; XIA, Y.; BEX, V.; MIDGLEY, P.M. (Ed.). Climate change 2013: the physical science basis. Contribution of Working Group I to the Fifth Assessment Report of the Intergovernmental Panel on Climate Change. Cambridge: Cambridge University, 2013. 33p.

KRISHNAN, P.; SWAIN, B.; CHANDRA BHASKAR, B.; NAYAK, S.K.; DASH, R.N. Impact of elevated $\mathrm{CO}_{2}$ and temperature on rice yield and methods of adaptation as evaluated by crop simulation studies. Agriculture, Ecosystems and Environment, v.122, p.233-242, 2007. DOI: 10.1016/j.agee.2007.01.019.

KUMAR, A.; SHARMA, P.; AMBRAMMAL, S.K. Climatic effects on food grain productivity in India: a crop wise analysis. Journal of Studies in Dynamics and Change, v.1, p.38-48, 2014.

LAGO, I.; STRECK, N.A.; ALBERTO, C.M.; OLIVEIRA, F.B.; PAULA, G.M. de. Impact of increasing mean air temperature on the development of rice and red rice. Pesquisa Agropecuária Brasileira, v.43, p.1441-1448, 2008. DOI: 10.1590/ S0100-204X2008001100001.

MARSLAND, S.J.; HAAK, H.; JUNGCLAUS, J.H.; LATIF, M.; RÖSKE, F. The Max-Planck-Institute global ocean/sea ice model with orthogonal curvilinear coordinates. Ocean Modelling, v.5, p.91-127, 2003. DOI: 10.1016/S1463-5003(02)00015-X. 
MATSUI, T.; NAMUCO, O.S.; ZISKA, L.H.; HORIE, T. Effects of high temperature and $\mathrm{CO}_{2}$ concentration on spikelet sterility in Indica rice. Field Crops Research, v.51, p.213-219, 1997. DOI: 10.1016/S0378-4290(96)03451-X.

MATTHEWS, R.B.; KROPFF, M.J.; HORIE, T.; BACHELET, D. Simulating the impact of climate change on rice production in Asia and evaluating options for adaptation. Agricultural Systems, v.54, p.399-425, 1997. DOI: 10.1016/S0308-521X(95)00060-I.

MOTA, F.S. da. Disponibilidade de radiação solar e risco de frio no período reprodutivo do arroz irrigado em diferentes regiões do Rio Grande do Sul. Lavoura Arrozeira, v.48, p.8-10, 1995.

MOTA, F.S. da; ROSSKOFF, J.L. da C.; SILVA, J.B. da. Probabilidade de ocorrência de dias com temperaturas iguais ou superiores a $35^{\circ} \mathrm{C}$ no florescimento do arroz no Rio Grande do Sul. Revista Brasileira de Agrometeorologia, v.7, p.147-149, 1999.

ROSA, H.T. Simulação do crescimento, desenvolvimento e produtividade de arroz no Rio Grande do Sul com o modelo SimulArroz. 2013. 96p. Tese (Doutorado) - Universidade Federal de Santa Maria, Santa Maria.

SIQUEIRA, O.J.W. de; STEINMETZ, S.; FERREIRA, M.F.; COSTA, A. C.; WOZNIAK, M.A. Mudanças climáticas projetadas através dos modelos GISS e reflexos na produção agrícola brasileira. Revista Brasileira de Agrometeorologia, v.8, p.311-320, 2000.

SOLOMON, S.; QIN, D.; MANNING, M.; CHEN, Z.; MARQUIS, M.; AVERYT, K.B.; TIGNOR, M.; MILLER, H.L. (Ed.). Climate change 2007: the physical science basis. Contribution of Working Group I to the Fourth Assessment Report of the Intergovernmental Panel on Climate Change. Cambridge: IPCC, 2007. 996p.

STEINMETZ, S.; ASSIS, F.N. de; BURIOL, G.A.; ESTEFANEL, V.; AMARAL, A.G.; FERREIRA, J.S.A. Mapeamento das probabilidades de ocorrência de temperaturas mínimas do ar, durante o período reprodutivo do arroz irrigado, no Estado do Rio Grande do Sul. Revista Brasileira de Agrometeorologia, v.11, p.169-179, 2003.

STRECK, N.A. Climate change and agroecosystems: the effect of elevated atmospheric $\mathrm{CO}_{2}$ and temperature on crop growth, development, and yield. Ciência Rural, v.35, p.730-740, 2005. DOI: 10.1590/S0103-84782005000300041.

STRECK, N.A.; ALBERTO, C.M. Estudo numérico do impacto da mudança climática sobre a produtividade de trigo, soja e milho.
Pesquisa Agropecuária Brasileira, v.41, p.1351-1359, 2006 a. DOI: 10.1590/S0100-204X2006000900002.

STRECK, N.A.; ALBERTO, C.M. Simulação do impacto da mudança climática sobre a água disponível do solo em agroecossistemas de trigo, soja e milho em Santa Maria, RS. Ciência Rural, v.36, p.424-433, 2006b. DOI: 10.1590/ S0103-84782006000200011.

STRECK, N.A.; BOSCO, L.C.; LAGO, I. Simulating leaf appearance in rice. Agronomy Journal, v.100, p.490-501, 2008. DOI: 10.2134/agronj2007.0156.

STRECK, N.A.; CHARÃO, A.S.; WALTER, L.C.; ROSA, H.T.; BENEDETTI, R.P.; MARCHESAN, E.; SILVA, M.R. da. SimulArroz: um aplicativo para estimar a produtividade de arroz no Rio Grande do Sul. In: CONGRESSO BRASILEIRO DE ARROZ IRRIGADO, 8., 2013, Santa Maria. Anais. Santa Maria: SOSBAI, 2013a. p.1618-1627.

STRECK, N.A.; UHLMANN, L.O.; GABRIEL, L.F. Leaf development of cultivated rice and weedy red rice under elevated temperature scenarios. Revista Brasileira de Engenharia Agrícola e Ambiental, v.17, p.190-199, 2013b. DOI: 10.1590/ S1415-43662013000200010.

UNITED STATES DEPARTMENT OF AGRICULTURE. Foreign Agricultural Service. Production, supply and distribution online: custom query. 2014. Available at: $<$ http://www.fas.usda. gov/psdonline/psdQuery.aspx>. Accessed on: 11 Oct. 2014.

WALTER, L.C.; ROSA, H.T.; STRECK, N.A. Simulação do rendimento de grãos de arroz irrigado em cenários de mudanças climáticas. Pesquisa Agropecuária Brasileira, v.45, p.1237-1245, 2010. DOI: 10.1590/S0100-204X2010001100002.

WREGE, M.S.; STEINMETZ, S.; REISSER JÚNIOR, C.; ALMEIDA, I.R. de. (Ed.). Atlas climático da Região Sul: Estados do Paraná, Santa Catarina e Rio Grande do Sul. Pelotas: Embrapa Clima Temperado; Colombo: Embrapa Florestas, 2011. $333 p$.

YANG, L.; HUANG, J.Y.; YANG, H.J.; DONG, G.; LIU, G.; ZHU, J.; WANG, Y. Seasonal changes in the effects of free-air $\mathrm{CO}_{2}$ enrichment (FACE) on dry matter production and distribution of rice (Oryza sativa L.). Field Crops Research, v.98, p.12-19, 2006. DOI: $10.1016 /$ j.fcr.2005.11.003.

Recebido em 21 de maio de 2014 e aprovado em 12 de outubro de 2014 